\title{
The ontogeny of exploratory behaviors in early-protein-malnourished rats exposed to the elevated plus-maze test
}

\author{
SEBASTIÃO S. ALMEIDA, RICARDO A. GARCIA, MARGARIDA M. R. CIBIEN, \\ MARIELENA DE ARAUJO, GABRIELA M. S. MOREIRA, and LUIZ M. DE OLIVEIRA \\ University of São Paulo, Ribeirão Preto, São Paulo, Brazil
}

\begin{abstract}
An elevated plus-maze was used to study the ontogeny of the exploratory behaviors of earlyprotein-malnourished animals in an experimental aversive situation. Rats were malnourished by feeding their dams a $6 \%$ protein diet during the lactation period ( $0-21$ days of age); controls received a 16\% protein diet. From 21 to 100 days of age, all rats received a balanced lab chow diet. At 21, 30, $40,50,60,70,80,90$, and 100 days of age, independent groups of malnourished and control animals were exposed to the elevated plus-maze and allowed to explore for $5 \mathrm{~min}$. During this period, $12 \mathrm{be}$ havioral categories (number of entries and time spent in the open and enclosed arms, total arms entries, attempts to enter open and closed arms, closed-arm returns, latency of first closed-arm entry, total immobility time, total grooming time, total rearings, total head-dippings, and total stretch attend posture) were recorded. The results showed that anxiety increased with age and that protein malnutrition produced alterations in the ontogeny of exploratory behaviors. It was shown that malnourished rats maintained or increased exploration in the maze with age, in contrast to wellnourished animals, which exhibited a steady decrease in exploration as they matured. The higher number of entries and time spent in the open arms suggest that the protein malnutrition causes a permanent increase in the impulsiveness and/or an increased drive to explore open-arm novelty, leading to a behavior consistent with lower anxiety in malnourished animals, relative to that in wellnourished animals, in this naturalistic animal model of anxiety.
\end{abstract}

Protein malnutrition early in life causes long-lasting structural and neurochemical changes in the central nervous system, as well as behavioral abnormalities (Dobbing, 1987; Morgane et al., 1993; Morgane, AustinLaFrance, Bronzino, Tonkiss, \& Galler, 1992; Tonkiss, Galler, Morgane, Bronzino, \& Austin-LaFrance, 1993). Concerning the behavioral alterations, it has been described that malnourished animals showed higher transitions in the light-dark transition test (Brioni \& Orsingher, 1988), slower acquisition of a differential-reinforcementof-low-rates (DRL) operant procedure (Brioni \& Orsingher, 1988; Tonkiss, Galler, Formica, Shukitt-Hale, \& Timm, 1990), higher percentage of entries in the open arms in the elevated plus-maze test (Almeida, De Oliveira, \& Graeff, 1991), and an increased number of rearings and attempts to enter open arms in the plus-maze (Almeida,

This work was supported by Research Grant 90/3474-0 from the Fundacão de Amparo à Pesquisa do Estado de São Paulo and Grant 40015/91-9 from the Conselho Nacional de Desenvolvimento Científico e Tecnológico. We thank John Tonkiss for comments on a draft of this manuscript and Dalmo C. P. Nicola for technical assistance. S. S. Almeida and L. M. de Oliveira were recipients of research fellowships from the Conselho Nacional de Desenvolvimento Cientifico e Tecnológico. Correspondence should be addressed to S. S. Almeida, whose present address is Center of Behavioral Development and Mental Retardation, M921B, Boston University School of Medicine, $80 \mathrm{E}$. Concord St., Boston, MA 02118 (e-mail: sdalmei@acs,bu.edu).
Garcia, \& De Oliveira, 1993). The study describing increased exploration of the open arms (Almeida et al., 1991) used rats malnourished during lactation and postlactation periods and tested at 70 days of age after a nutritional recovery period. This increased exploration of the open arms in the elevated plus-maze may suggest lower anxiety and/or higher impulsiveness of malnourished animals or even a delay in the ontogeny of exploratory behaviors in an anxiety situation. The hypothesis of delay in the ontogeny of these behaviors is an idea that is reinforced by a great number of publications in the area of malnutrition describing behavioral and/or neurochemical abnormalities in malnourished animals that disappear later in life even if the animals remain under the malnourishment procedure (Agarwal, Prassad, \& Taneja, 1981; Almeida, Soares, Bichuette, Graeff, \& De Oliveira, 1992; Wiggins, Fuller, \& Enna, 1984). As the anxiety in the elevated plus-maze increases with age (Imhof, Coelho, Schmitt, Morato, \& Carobrez, 1993), then a developmental delay due to malnutrition could be producing differences in the time of maturational process of some neural structures that underlie inhibitory behaviors displayed in aversive situations and leading to the behavioral differences between malnourished and control animals in this test.

In order to study whether this greater proportion of open-arm exploration produced by lactational plus postlactational malnutrition is also present in animals mal- 
nourished only during the lactational phase and whether this greater exploration could be a result of a delay in the development of inhibitory behaviors in aversive situations, in the present investigation we used an ethological analysis (as described by Rodgers \& Cole, 1993a, $1993 \mathrm{~b}$ ) of the exploratory behaviors in rats malnourished from birth to 21 days of age and submitted to the elevated plus-maze in different ages during the nutritional recovery period. The elevated plus-maze paradigm is a model of anxiety based on the natural aversion of rodents to heights and open spaces (Montgomery, 1958 ) and has been validated for rats (Pellow, Chopin, File, \& Briley, 1985) and mice (Lister, 1987). In this model, the percentage of entries and the time spent in the open arms are taken as measures of anxiety, and the total arm entries (open + closed) provide a measure of overall activity. Placing the rat on the central platform of the maze can evoke both the exploratory drive and the fear drive, thus generating an approach-avoidance conflict behavior. This test was chosen for the present study, since it has a higher degree of ecological validity than do traditional operant procedures and does not require extensive training or the use of noxious stimuli (Handley \& McBlane, 1993; Lister, 1990).

\section{METHOD}

\begin{abstract}
Subjects
Two hundred sixteen male Wistar rats were used from the animal house of Ribeirão Preto Campus of the University of São Paulo. Within $12 \mathrm{~h}$ of birth, the male pups were weighed and randomly assigned to a litter of 6 per dam. The dams and pups were placed in transparent plastic cages $(35 \times 30 \times 20 \mathrm{~cm})$ and randomly assigned to receive either a $6 \%$ (malnourished, $\mathrm{M}$ ) or a $16 \%$ (well-nourished, $\mathrm{W}$ ) protein diet ad lib. The two diets were isocaloric and prepared according to Almeida et al. (1992). The protein-deficient diet contained $6 \%$ protein (casein), $5 \%$ salt mixture, $1 \%$ vitamin mixture, $8 \%$ corn oil, $0.2 \%$ choline, and $77.8 \%$ cornstarch. The normal protein diet contained $16 \%$ protein, $60.8 \%$ cornstarch, and the same percentage of the other constituents as in the protein-deficient diet. Because casein is deficient in the amino acid methionine, the two diets were supplemented with L-Methionine $(2 \mathrm{~g} / \mathrm{kg}$ of protein). The litters were maintained on these diets until the end of lactation period (21st day). After weaning, the pups were housed in individual metal cages $(20 \times 25 \times 15 \mathrm{~cm})$ and were fed a balanced lab chow diet. The rats were maintained under 12:12-h light:dark cycle (lights on at 7 a.m.), and room temperature was kept at $23^{\circ}-25^{\circ} \mathrm{C}$. Behavioral testing occurred between 2 p.m. and 5 p.m.
\end{abstract}

\section{Apparatus}

The elevated plus-maze was made of wood and consisted of two open arms $(50 \times 10 \mathrm{~cm})$ opposite to each other, crossed by two enclosed arms $(50 \times 10 \times 40 \mathrm{~cm})$ with an open roof (Pellow et al., 1985). The maze was elevated $50 \mathrm{~cm}$ from the ground floor. Fluorescent light $(2 \times 60 \mathrm{~W})$ from the ceiling provided the only illumination for the experimental room.

\section{Procedure}

At $21,30,40,50,60,70,80,90$, and 100 days of age, independent groups of $\mathrm{M}$ and $\mathrm{W}$ animals $(n=12)$ were submitted to the elevated plus-maze test. The rats were placed individually in the center of the maze facing an enclosed arm and allowed to explore for $5 \mathrm{~min}$. The test session was recorded with a Sony videocamera linked to a monitor and VCR in an adjacent room. The videotapes were analyzed by two experimenters blind to the nutritional and age conditions, and 12 behavioral categories (as modified from Rodgers \& Cole, 1993a, 1993b) were recorded. These behavioral categories comprised traditional and novel plus-maze measures. Traditional parameters were number of open- and closed-arm entries (arm entry defined as all four paws into an arm), total rears, attempts to enter open arms, attempts to enter closed arms, and time spent in open and closed arms (Almeida et al., 1993). In addition, we recorded a range of specific behaviors related to the defensive repertoire of the rat. These included the first closed-arm entry latency (latency to enter a closed arm timed from the start of the test) and immobility time (remaining motionless without engaging in any behavioral act) and time of grooming (licking paws, moving paws over head from ears to snout, licking body, and scratching flanks with a hind paw). In addition, we recorded behavior categories described by Rodgers and Cole (1993a, 1993b) as risk assessment behaviors. These measures comprised (1) closedarm returns (exiting a closed arm with the forepaws only and then returning into the same arm), (2) head-dipping (scanning over the sides of the maze toward the floor, occurring from the relative security of a closed arm exit or the center platform), and (3) stretch attend (forward elongation of head and shoulders followed by retraction to original position; this posture occurs with highest frequency on the center platform - particularly toward open armsand at the exit of the closed arms-toward center platform and open arms).

\section{Statistical Analyses}

The body weight and behavioral measures were analyzed by a two-factor (diet and age) analysis of variance (ANOVA). Post hoc comparisons were made by Newman-Keuls test (Bruining \& Kintz, 1977).

\section{RESULTS}

\section{Body Weight}

Malnutrition during the lactation period produced lower body weight that was not recovered even after 11 weeks of nutritional rehabilitation $[F(1,264)=134.03$, $p<.001]$. The animals of the two nutritional conditions increased their body weight at the same rate as evidenced by a significant effect of age factor $[F(11,264)=$ $162.75, p<.01]$, and there were no differences in the interaction between diet condition and age. Body weight on Day 100 was $341 \pm 12 \mathrm{~g}$ and $410 \pm 16 \mathrm{~g}$ for $\mathrm{M}$ and W rats, respectively.

\section{Behavioral Measures}

As illustrated in Figure 1, malnutrition during the lactation period increased both the percentage of entries and the time spent in the open arms, relative to controls in the majority of ages studied. These differences due to nutritional conditions were evidenced by significant main effects of diet on both the percentage of open-arm entries $[F(1,198)=5.25, p<.02]$, and the percentage of time spent in the open arms $[F(1,198)=3.75, p<.05]$. The statistical analysis also showed differences in the ontogeny of the exploratory behavior as evidenced by a significant effect of interaction between nutritional conditions and ages tested in both the percentage of open- 

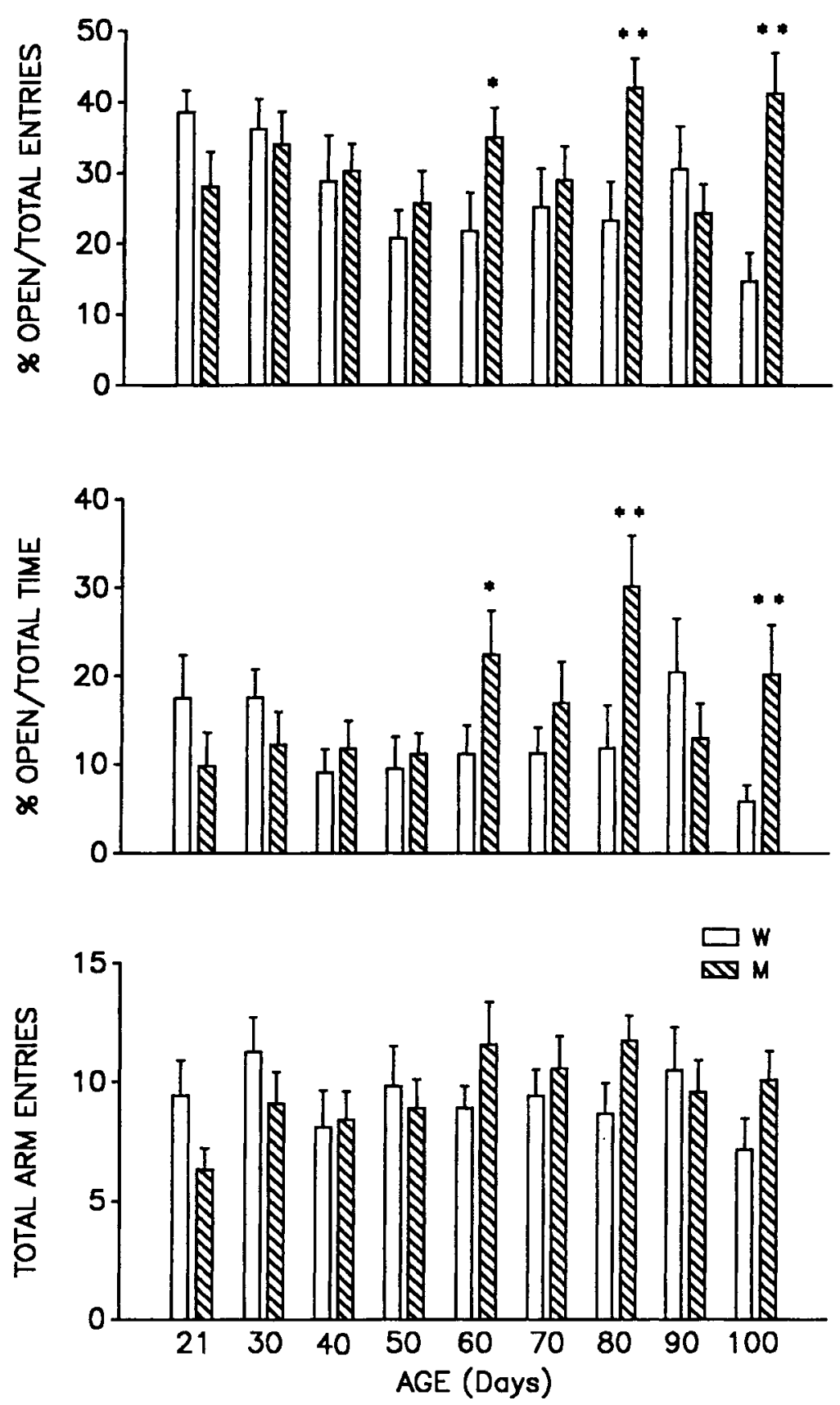

Figure 1. Percentage of entries (top) and time spent (middle) in the open arms of the maze and total arm entries (bottom) made by malnourished (M) and well-nourished (W) animals at various ages. Values represent the mean $\pm S E M$ of 12 rats in each condition. ${ }^{*} p<.06 . \quad{ }^{* *} p<.01$, relative to $W$ animals at the same age.

arm entries $[F(8,198)=3.27, p<.001]$ and time spent in the open arms $[F(8,198)=2.72, p<.01]$. The post hoc analysis showed significant differences between $M$ and $\mathrm{W}$ rats at 80 and 100 days of age $(p<.01)$ and a tendency to the significance at 60 days of age $(p<.06)$ for both entries and time spent in the open arms. No significant differences were found regarding the total arm entries. Early malnutrition also produced an increased latency to the first closed-arm entry as evidenced by a significant main effect of diet $[F(1,198)=4.97, p<.02]$ (see Table 1).

Regarding the other behavioral categories, significant effects of age were found for attempts to enter open arms $[F(8,198)=6.14, p<.001]$, closed-arm returns $[F(8,198)=2.19, p<.05]$, immobility time $[F(8,198)=$ $2.53, p<.01]$, rearing $[F(8,198)=2.26, p<.02]$, headdipping $[F(1,198)=5.87, p<.001]$, and stretch attend $[F(8,198)=4.13, p<.001]($ Table 1$)$. No main effect of 
Table 1

Mean $\pm S E M$ of Behavioral Categories Recorded in the Elevated Plus-Maze in Different Ages for the Two Diet Conditions (M and W)

\begin{tabular}{|c|c|c|c|c|c|c|c|c|c|c|}
\hline \multirow{2}{*}{$\begin{array}{l}\text { Behavioral } \\
\text { Categories }\end{array}$} & \multirow{2}{*}{$\begin{array}{c}\text { Diet } \\
\text { Condition }\end{array}$} & \multicolumn{9}{|c|}{ Age (Days) } \\
\hline & & 21 & 30 & 40 & 50 & 60 & 70 & 80 & 90 & 100 \\
\hline \multirow{2}{*}{$\mathrm{LCE}^{*}$} & $\mathrm{M}$ & $2.4 \pm 0.6$ & $1.0 \pm 0.3$ & $3.2 \pm 0.9$ & $1.8 \pm 0.5$ & $6.0 \pm 2.1$ & $3.6 \pm 1.3$ & $5.3 \pm 2.0$ & $3.2 \pm 0.9$ & $4.6 \pm 1.2$ \\
\hline & W & $1.8 \pm 0.5$ & $1.8 \pm 0.6$ & $1.4 \pm 0.4$ & $3.2 \pm 1.7$ & $2.0 \pm 0.7$ & $3.7 \pm 1.9$ & $2.5 \pm 1.2$ & $2.3 \pm 0.8$ & $1.5 \pm 0.4$ \\
\hline \multirow{2}{*}{ ITt } & $\mathrm{M}$ & $20.2 \pm 5.8$ & $1.4 \pm 0.7$ & $3.2 \pm 1.1$ & $4.3 \pm 1.8$ & $1.7 \pm 0.6$ & $4.8 \pm 1.8$ & $5.4 \pm 1.6$ & $6.2 \pm 2.3$ & $6.4 \pm 2.3$ \\
\hline & W & $9.8 \pm 5.3$ & $3.7 \pm 1.7$ & $2.3 \pm 1.1$ & $4.6 \pm 2.0$ & $8.7 \pm 3.4$ & $3.4 \pm 1.7$ & $7.2 \pm 2.8$ & $5.3 \pm 2.2$ & $2.4 \pm 1.2$ \\
\hline \multirow{2}{*}{ AEO $†$} & $\mathrm{M}$ & $1.0 \pm 0.2$ & $2.2 \pm 0.6$ & $2.9 \pm 0.4$ & $3.2 \pm 0.6$ & $5.0 \pm 0.8$ & $5.3 \pm 1.0$ & $3.7 \pm 0.6$ & $4.3 \pm 0.9$ & $3.0 \pm 0.5$ \\
\hline & W & $1.5 \pm 0.4$ & $2.9 \pm 0.5$ & $4.1 \pm 0.6$ & $4.2 \pm 0.8$ & $5.0 \pm 0.8$ & $5.0 \pm 0.3$ & $4.5 \pm 0.4$ & $3.5 \pm 0.7$ & $3.9 \pm 1.0$ \\
\hline \multirow{2}{*}{ CAR $\dagger$} & $\mathbf{M}$ & $0.3 \pm 0.2$ & $1.3 \pm 0.3$ & $1.1 \pm 0.3$ & $1.1 \pm 0.3$ & $1.0 \pm 0.3$ & $2.0 \pm 0.6$ & $0.6 \pm 0.2$ & $1.1 \pm 0.6$ & $0.8 \pm 0.2$ \\
\hline & W & $0.3 \pm 0.2$ & $1.1 \pm 0.4$ & $1.4 \pm 0.3$ & $1.3 \pm 0.4$ & $1.5 \pm 0.3$ & $1.4 \pm 0.3$ & $1.4 \pm 0.4$ & $1.1 \pm 0.3$ & $1.5 \pm 0.5$ \\
\hline \multirow{2}{*}{$\mathrm{TR} \dagger$} & M & $0.3 \pm 0.2$ & $1.1 \pm 0.9$ & $0.8 \pm 0.3$ & $1.2 \pm 0.4$ & $1.6 \pm 0.4$ & $2.0 \pm 0.5$ & $2.3 \pm 0.6$ & $2.0 \pm 0.6$ & $1.6 \pm 0.4$ \\
\hline & W & $0.5 \pm 0.3$ & $1.8 \pm 0.6$ & $0.9 \pm 0.4$ & $0.6 \pm 0.3$ & $1.0 \pm 0.4$ & $1.4 \pm 0.4$ & $1.6 \pm 0.5$ & $1.5 \pm 0.5$ & $0.9 \pm 0.2$ \\
\hline \multirow{2}{*}{ THD $\dagger$} & $\mathrm{M}$ & $2.4 \pm 0.4$ & $3.6 \pm 0.7$ & $6.2 \pm 1.0$ & $7.0 \pm 1.0$ & $10.2 \pm 1.3$ & $10.3 \pm 1.4$ & $8.4 \pm 1.2$ & $7.6 \pm 1.3$ & $8.7 \pm 1.2$ \\
\hline & W & $5.2 \pm 0.8$ & $6.2 \pm 1.0$ & $7.3 \pm 1.4$ & $7.2 \pm 1.3$ & $8.8 \pm 1.3$ & $9.1 \pm 3.3$ & $7.7 \pm 0.8$ & $8.2 \pm 1.2$ & $7.3 \pm 1.5$ \\
\hline \multirow{2}{*}{ TSAP $\dagger$} & $\mathrm{M}$ & $0.2 \pm 0.1$ & $0.9 \pm 0.3$ & $2.2 \pm 0.4$ & $1.7 \pm 0.6$ & $1.3 \pm 0.4$ & $1.0 \pm 0.3$ & $1.0 \pm 0.3$ & $1.0 \pm 0.3$ & $1.3 \pm 0.3$ \\
\hline & W & $0.1 \pm 0.1$ & $1.2 \pm 0.5$ & $2.2 \pm 0.4$ & $1.8 \pm 0.7$ & $1.3 \pm 0.4$ & $1.0 \pm 0.4$ & $1.7 \pm 0.3$ & $0.9 \pm 0.3$ & $2.2 \pm 0.5$ \\
\hline
\end{tabular}

Note $-\mathrm{M}=$ malnourished; $\mathrm{W}=$ well nourished; $\mathrm{LCE}=$ latency of first closed-arm entry; IT = immobility time; AEO = attempts to enter open arms; $\mathrm{CAR}=$ closed-arm returns; TR $=$ total rears; THD $=$ total head-dips; TSAP = total stretch attend posture. $\quad$ *Significant effect of diet. †Significant effect of age.

diet or interaction between diet and age was found. The main effect of age observed in these categories was due mainly to an increased number of/or time spent in these behaviors as the age increased. The other two categories (attempts to enter closed arms and grooming time) were not affected by any of the variables studied.

\section{DISCUSSION}

The lower body weight of malnourished animals supports previously reported results showing that a proteindeficient diet during the lactation period impairs normal development and that even a prolonged nutritional recovery period is not sufficient to equalize the body weights of malnourished and well-nourished animals. These long-lasting effects of early protein malnutrition on development of body and brain have been well described by us (Almeida et al., 1993; De Oliveira \& Almeida, 1985; Lima, Oliveira, Lachat, Dal-Bo, \& Almeida, 1993) and by others (Dobbing, 1987; Morgane et al., 1978).

In relation to the behavioral categories analyzed in the elevated plus-maze, it was found that malnourished rats were different from the controls on the percentage of entries and the time spent in the open arms, as well as in the latency of first closed-arm entry. As demonstrated in a previous study with rats malnourished during lactation and postlactation periods and tested at 70 days of age (Almeida et al., 1991), the present results showed that rats malnourished only during the lactation period also exhibit, in the elevated plus-maze, a behavior consistent with a lower anxiety, relative to that of controls. Thus, they enter the open arms more often and spend more time in the open arms of the maze than do wellnourished rats. Consistent with this lower anxiety level in the malnourished rats, the present data showed that these animals also spent more time in the open arms and/or central platform of the maze before the first closed-arm entry. This higher latency could not be attributed to more time in freezing behavior and/or locomotor activity, because we did not find differences due to diet condition on the immobility time and total arm entries. In addition, the highly significant interaction between diet condition and age of rats in the percentage of entries and time spent in the open arms (a result mainly due to results found at 60,80 , and 100 days of age) evidenced clear differences in the ontogeny of these exploratory behaviors in the elevated plus-maze. While $\mathrm{W}$ animals decreased open-arm exploration as their age increased-a result similar to recently published findings using animals maintained with standard lab chow diet (Imhof et al., 1993)- $\mathrm{M}$ animals maintained the initial exploratory level or even increased this in later ages (see Figure 1). These results suggest a permanent effect of malnutrition rather than a developmental delay in the ontogeny of exploratory behaviors in the elevated plusmaze. In effect, the differences between $M$ and $W$ rats increased as they recovered nutritionally from the early exposition to a protein-deficient diet. This high level of open-arm exploration in the $\mathrm{M}$ rats may indicate a stronger exploratory drive and/or a decreased habituation to the novel environment, or even an increase in the impulsiveness produced by early protein malnutrition. This later explanation appears to be more plausible since it has been demonstrated that rats malnourished during both postnatal (Brioni \& Orsingher, 1988) and prenatal (Tonkiss et al., 1990) periods make more transitions in a light-dark test and demonstrate slower acquisition of a DRL procedure (an operant task requiring that the animals respond infrequently upon a lever in order to obtain reward-a good indicator of behavioral inhibition or "impulsiveness"). In addition, it has been demonstrated (Almeida et al., 1993) that lactational malnourished rats spend more time on the central platform of the maze and rear more on this central platform when repeatedly exposed to the plus-maze, perhaps indicating more explo- 
ration in the "decision area" of the maze. The lack of differences at ages 70 and 90 days cannot be explained at the present time.

This proposed high impulsiveness of $M$ rats could be the result of deleterious effects of malnutrition on brain structures underlying inhibitory behaviors in situations promoting anxiety. Recently, it has been demonstrated that protein malnutrition during gestation impairs the normal development of hippocampal (Diaz-Cintra et al., 1991; Garcia-Ruiz, Diaz-Cintra, Cintra, \& Corkidi, 1993) and amygdaloid (Escobar \& Salas, 1993) areas. Specifically with relation to amygdala, it was demonstrated that protein malnutrition produced a reduced somatic area of the neurons in the basolateral, central, and medial nuclei of the amygdaloid complex and a significant decrease in the number of dendritic branches in the neurons of basolateral and central nuclei. It has been demonstrated that the hippocampal formation and amygdaloid complex are evolved in the process of learning and memory associated with novel and stress situations (Henke, 1983; LeDoux, 1993; Liang \& Lee, 1988; Teyler \& DiScenna, 1984), mainly through the mobilization of central GABAergic and serotonergic systems (File, Zangrossi, \& Andrews, 1993; Guimarães, Del Bel, Padovan, Mendonça, Netto, \& Almeida, 1993; Plaznik, Jessa, Bidzinski, \& Nazar, 1994). In addition, since prenatal and/or postnatal protein malnutrition produces marked alterations in the structure (Cintra, Diaz-Cintra, Galvan, Kemper, \& Morgane, 1990; Jordan, Howells, McNaugthon, \& Heatlie, 1982; Lewis, Patel, \& Balaz, 1979), neurophysiology (Bronzino, Austin-LaFrance, \& Morgane, 1990, 1991a, 1991b; Jordan \& Clark, 1983), and neurochemistry (Chen, Tonkiss, Galler, \& Volicer, 1992) of hippocampal formation and since impaired development of amygdaloid areas could also follow the lactational malnutrition, the differences in the emotional response of malnourished rats in the present study could be, at least in part, explained by changes in morphology, neurophysiology, and neurochemistry of these brain structures. However, although consistent effects of postnatal malnutrition have been well demonstrated in the hippocampal formation, further studies are necessary to investigate the impact of this malnutrition procedure on developmental aspects of amygdaloid areas.

On the other hand, the apparent lower anxiety of $M$ animals in the plus-maze contrasts with previous data using painful aversive stimuli, the great majority of which demonstrated a higher emotional reaction of malnourished rats to electric shock (Almeida, De Oliveira, Bichuette, \& Graeff, 1988; Almeida et al., 1992; De Oliveira \& Almeida, 1985; Levitsky \& Barnes, 1972; Smart, Whatson, \& Dobbing, 1985). However, this difference may be attributed to the lower shock thresholds demonstrated by malnourished animals (Levitsky \& Barnes, 1972; Smart et al., 1985). It is possible that in more naturalistic (presumably less intensely) aversive situations (as the elevated plus-maze model), the higher impulsiveness of malnourished animals supplants the fear drive, leading the animals to greater exploration of the potentially aversive environment. In accord with this interpretation is the finding of more transitions of malnourished rats in a light-dark test (Brioni \& Orsingher, 1988) and more open-arm exploration in the elevated plus-maze (Almeida et al., 1991; Almeida et al., 1993).

The absence of a main effect of diet or interactions between diet and age in the behaviors designed to measure risk assessment indicates that with this malnutrition procedure this class of behavior was not altered and that the better measures to demonstrate differences between $M$ and $\mathrm{W}$ rats are the classical measures described by Pellow et al. (1985). An exception to this was for the latency to first closed-arm entry, where the $M$ animals demonstrated a higher latency than did controls. However, a significant main effect of age in the majority of these measures indicates that this is a useful model to investigate the ontogeny of behaviors related to the defensive repertoire of the rat in a naturalistic situation. In effect, the great majority of behavioral categories analyzed showed that anxiety increased as the rats matured, a result consistent with previous reported data (Imhof et al., 1993).

In summary, the elevated plus-maze model was shown to be useful for studying the ontogeny of behaviors related to the defensive repertoire of the rat in a naturalistic anxiety situation and was sensitive to detect ontogenetic differences between lactational malnourished and well-nourished rats related to exploration of maze open arms. In addition, these differences between $\mathrm{M}$ and $\mathrm{W}$ rats suggest a permanent increase of impulsiveness in the $\mathrm{M}$ rats as a result of early malnutrition rather than a delay in the ontogeny of the anxiety behaviors, as a more detailed analysis of our previously reported studies (Almeida et al., 1991; Almeida et al., 1993) appeared to indicate. Finally, it was demonstrated that malnutrition during the lactation period is sufficient to produce increases in the exploration of the elevated plus-maze in a fashion similar to that demonstrated with lactational plus postlactational malnutrition in our laboratory (Almeida et al., 1991).

\section{REFERENCES}

Agarwal, K. N., Prassad, C., \& Taneja, V. (1981). Protein deprivation and the brain: Effect of enzymes and free aminoacids related to glutamate metabolism in rats. Annals of Nutritional Metabolism, 25, 228-233.

Almeida, S. S., De Oliveira, L. M., Bichuette, M. Z., \& GraefF, F. G. (1988). Early malnutrition alters the effect of chlordiazepoxide on inhibitory avoidance. Brazilian Journal of Medical \& Biological Research, 21, 1033-1036.

Almeida, S. S., De Oliveira, L. M., \& Graeff, F. G. (1991). Early protein malnutrition changes exploration of the elevated plus-maze and reactivity to anxiolytics. Psychopharmacology, 103, 513-518.

Almeida, S. S., Garcia, R. A., \& De Oliveira, L. M. (1993). Effects of early protein malnutrition and repeated testing upon locomotor and exploratory behaviors in the elevated plus-maze. Physiology \& Behavior, 54, 749-752.

Almeida, S. S., Soares, E. G., Bichuette, M. Z., Graeff, F. G., \& De Oliveira, L. M. (1992). Effects of early postnatal malnutrition and chlordiazepoxide on experimental aversive situations. Physiology \& Behavior, 51, 1195-1199.

Brioni, J. D., \& OrSingher, O. A. (1988). Operant behavior and re- 
activity to the anticonflict effect of diazepam in perinatally undernourished rats. Physiology \& Behavior, 44, 193-198.

Bronzino, J. D., Austin-LaFrance, R. J., \& Morgane, P. J. (1990). Effects of prenatal protein malnutrition on perforant path kindling in the rat. Brain Research, 515, 45-50.

Bronzino, J. D., Austin-LaFrance, R. J., \& Morgane, P. J. (1991a). Effects of prenatal protein malnutrition on kindling-induced alteration in dentate granule cell excitability: I. Synaptic transmission measures. Experimental Neurology, 112, 206-215.

Bronzino, J. D., Austin-LaFrance, R. J., \& Morgane, P. J. (1991b). Effects of prenatal protein malnutrition on kindling-induced alteration in dentate granule cell excitability: II. Paired-pulse measures. Experimental Neurology, 112, 216-223.

Bruning, J. L., \& KinTZ, B. L. (1977). Computational handbook of statistics. Glenview, IL: Scott, Foresman.

Chen, J., Tonkiss, J., Galler, J. R., \& Volicer, L. (1992). Prenatal protein malnutrition in rats enhances serotonin release from hippocampus. Journal of Nutrition, 122, 2138-2143.

Cintra, L., Diaz-Cintra, S., Galvan, A., Kemper, T., \& Morgane, P. J. (1990). Effects of protein undernutrition on the dentate gyrus in rats of three age groups. Brain Research, 532, 271-277.

De Oliveira, L. M., \& Almeida, S. S. (1985). Effects of malnutrition and environment on the acquisition and extinction of avoidance behavior in rats. Physiology \& Behavior, 34, 141-145.

Diaz-Cintra, S., Cintra, L., Galvan, A., Aguilar, A., Kemper, T., \& MORGANE, P. J. (1991). Effects of prenatal protein deprivation on the postnatal development of granule cells in the fascia dentata. Journal of Comparative Neurology, 310, 356-364.

DoвBING, J. (1987). Early nutrition and later achievement. London: Academic Press.

Escobar, C., \& SALAS, M. (1993). Neonatal undernutrition and amygdaloid nuclear complex development: An experimental study in the rat. Experimental Neurology, 122, 311-318.

File, S. E., Zangrossi, H., JR., \& Andrews, N. (1993). Social interaction and elevated plus-maze tests: Changes in release and uptake of 5-HT and GABA. Neuropharmacology, 32, 217-221.

Garcia-Ruiz, M., Diaz-Cintra, S., Cintra, L., \& Corkidi, G. (1993). Effect of protein malnutrition on CA3 hippocampal pyramidal cells in rats of three ages. Brain Research, 625, 203-212.

Guimarães, F. S., Del Bel, E. A., Padovan, C. M., Mendonça Netto, S., \& Almeida, R. T. (1993). Hippocampal 5-HT receptors and consolidation of stressful memories. Behavioral Brain Research, 58, 133-139.

Handley, S. L., \& MCBlane, J. W. (1993). An assessment of the elevated $\mathrm{X}$-maze for studying anxiety and anxiety-modulating drugs. Journal of Pharmacological \& Toxicological Methods, 29, 129-138.

HENKE, P. G. (1983). Unit-activity in the central amygdalar nucleus of rats in response to immobilization-stress. Brain Research Bulletin, 10, 833-837.

Imhof, J. T., Coelho, M. I., Schmitt, M. L., Morato, G. S., \& Carobrez, A. P. (1993). Influence of gender and age on performance of rats in the elevated plus-maze apparatus. Behavioral Brain Research, 56, 177-180.

JORDAN, R. C., \& ClARK, G. A. (1983). Early undernutrition impairs hippocampal long-term potentiation in adult rats. Behavioral Neuroscience, 97, 319-322.

Jordan, R. C., Howells, K. F., McNaugthon, N., \& Heatlie, P. L. (1982). Effects of undernutrition on hippocampal development and function. Research in Experimental Medicine, 180, 201-207.

LEDoux, J. E. (1993). Emotional memory systems in the brain. Behavioral Brain Research, 58, 69-79.

LEVITSKY, D. A., \& BARNEs, R. H. (1972). Nutritional and environmental interaction in the behavior development of the rat: Longterm effects. Science, 176, 68-71.

LeWIS, P. D., PATEL, A. J., \& Balazs, R. (1979). Effect of undernutri- tion on cell generation in the rat hippocampus. Brain Research, $\mathbf{1 6 8}$, 186-189.

LiANG, K. C., \& LEE, E. H. (1988). Intra-amygdala injections of corticotropin releasing factor facilitate inhibitory avoidance learning and reduce exploratory behavior in rats. Psychopharmacology, 96, 232-236.

Lima, J. G., Oliveira, L. M., Lachat, J. J., Dal-Bo, C. M. R., \& Almeida, S. S. (1993). Comparison of the effects of lab chow and casein diets based on body and brain development of rats. Brazilian Journal of Medical \& Biological Research, 26, 1069-1076.

LISTER, R. G. (1987). The use of a plus-maze to measure anxiety in the mouse. Psychopharmacology, 92, 180-185.

LISTER, R. G. (1990). Ethologically based animal models of anxiety. Pharmacological Therapeutics, 46, 321-340.

MonTGOMERY, K. C. (1958). The relation between fear induced by novelty stimulation and exploratory behavior. Journal of Comparative Physiological Psychology, 48, 254-260.

Morgane, P. J., Austin-LaFrance, R., Bronzino, J., Tonkiss, J., Diaz-Cintra, S., Cintra, L., Kemper, T., \& Galler, J. R. (1993). Prenatal malnutrition and development of the brain. Neuroscience Biobehavioral Reviews, 17, 91-128.

Morgane, P. J., Austin-LaFrance, R. J., Bronzino, J. D., TONKISS, J., \& GALLER, J. R. (1992). Malnutrition and the developing central nervous system. In R. L. Isaacson \& K. F. Jensen (Eds.), The vulnerable brain and environmental risks: Vol. I. Malnutrition and hazard assessment (pp. 3-44). New York: Plenum.

Morgane, P., Miller, M., Kemper, T., Stern, W., Forbes, W., Hall, R., Bronzino, J., Kissane, J., Hawrylewicz, E., \& RESNICK, O. (1978). The effects of protein malnutrition and the developing central nervous system in the rat. Neuroscience \& Biobehavioral Reviews, 2, 137-230.

Pellow, S., Chopin, P., File, S. E., \& Briley, M. (1985). Validation of open:closed arm entries in an elevated plus-maze as a measure of anxiety in the rat. Journal of Neuroscience Methods, 14, 149-167.

PlazniK, A., Jessa, M., Bidzinski, A., \& NAzAR, M. (1994). The effect of serotonin depletion and intra-hippocampal midazolam on rat behavior in the Vogel conflict test. European Journal of Pharmacology, 257, 293-296.

Rodgers, R. J., \& Cole, J. C. (1993a). Anxiety enhancement in the murine elevated plus-maze by immediate prior exposure to social stressors. Physiology \& Behavior, 53, 383-388.

Rodgers, R. J., \& COLE, J. C. (1993b). Influence of social isolation, gender, strain, and prior novelty on plus-maze behavior in mice. Physiology \& Behavior, 54, 729-736.

Smart, J. L., Whatson, T. S., \& Dobing, J. (1985). Thresholds of response to electric shock in previously undernourished rats. British Journal of Nutrition, 34, 511-516.

TEYLER, T. J., \& DiScENNA, P. (1984). The topographical anatomy of the hippocampus: A clue to its function. Brain Research Bulletin, 12, 711-719.

Tonkiss, J., Galler, J. R., Formica, R. N., Shukitt-Hale, B., \& TIMM, R. R. (1990). Fetal protein malnutrition impairs acquisition of a DRL task in adult rats. Physiology Behavior, 48, 73-77.

Tonkiss, J., Galler, J. R., Morgane, P. J., Bronzino, J. D., \& Austin-LaFrance, R. J. (1993). Prenatal protein malnutrition and postnatal brain function. In C. L. Keen, A. Bendich, \& C. C. Willhite (Eds), Maternal nutrition and pregnancy outcome (Annals of the New York Academy of Sciences, Vol. 678, pp. 215-227). New York: New York Academy of Sciences.

WigGins, R., FUller, G., \& ENNA, S. (1984). Undernutrition and the development of brain neurotransmitter systems. Life Science, $\mathbf{3 5}$, 2085-2094.

(Manuscript received June 14, 1994; revision accepted for publication August 17, 1994.) 